Werner Kogge

Einführung in die Wissenschaften

Science Studies 
Werner Kogge lehrt Philosophie an der Freien Universität Berlin und leitet den Bereich Wissenschaftsphilosophie und Politische Theorie der DFG-Kollegforschungsgruppe "Strategies of Governance and Modes of Participation in the Ancient Near East«. Seine Forschungsschwerpunkte liegen im Feld von Methodologie, Wissenschaftstheorie, Politischer Theorie und Begriffsforschung. 
Werner Kogge

\section{Einführung in die Wissenschaften}

Wissenschaftstypen - Deutungskämpfe - Interdisziplinäre Kooperation 
Die Publikation wurde ermöglicht durch eine Ko-Finanzierung für Open-AccessMonografien und -Sammelbände der Freien Universität Berlin.

\section{Bibliografische Information der Deutschen Nationalbibliothek}

Die Deutsche Nationalbibliothek verzeichnet diese Publikation in der Deutschen Nationalbibliografie; detaillierte bibliografische Daten sind im Internet über http://dnb.d-nb.de abrufbar.

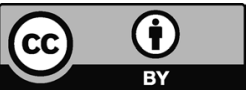

Dieses Werk ist lizenziert unter der Creative Commons Attribution 4.o Lizenz (BY). Diese Lizenz erlaubt unter Voraussetzung der Namensnennung des Urhebers die Bearbeitung, Vervielfältigung und Verbreitung des Materials in jedem Format oder Medium für beliebige Zwecke, auch kommerziell. (Lizenztext:

https://creativecommons.org/licenses/by/4.o/deed.de)

Die Bedingungen der Creative-Commons-Lizenz gelten nur für Originalmaterial. Die Wiederverwendung von Material aus anderen Quellen (gekennzeichnet mit Quellenangabe) wie z.B. Schaubilder, Abbildungen, Fotos und Textauszüge erfordert ggf. weitere Nutzungsgenehmigungen durch den jeweiligen Rechteinhaber.

\section{Erschienen 2022 im transcript Verlag, Bielefeld (c) Werner Kogge}

Umschlaggestaltung: Kordula Röckenhaus, Bielefeld Korrektorat: Jonas Geske, Bielefeld Druck: Majuskel Medienproduktion $\mathrm{GmbH}$, Wetzlar

Print-ISBN 978-3-8376-5970-2

PDF-ISBN 978-3-8394-5970-6

https://doi.org/10.14361/9783839459706

Buchreihen-ISSN: 2703-1543

Buchreihen-eISSN: 2703-1551

Gedruckt auf alterungsbeständigem Papier mit chlorfrei gebleichtem Zellstoff. Besuchen Sie uns im Internet: https://www.transcript-verlag.de Unsere aktuelle Vorschau finden Sie unter www.transcript-verlag.de/vorschau-download 